\title{
Late seizures in patients with internal carotid and middle cerebral artery occlusive disease following ischaemic events
}

\author{
P DE CAROLIS, ${ }^{*}$ R D' ALESSANDRO,${ }^{*}$ R FERRARA,${ }^{*}$ A ANDREOLI, $\dagger$ \\ T SACQUEGNA, ${ }^{*}$ E LUGARESI*
}

\begin{abstract}
From the Institute of Neurology, University of Bologna* and First Division of Neurosurgery, Bellaria Hospital, $\dagger$ Bologna, Italy
\end{abstract}

SUMMARY The occurrence of post-infarction epilepsy was investigated in 68 patients with angiographically proven internal carotid artery occlusion and in 56 patients with middle cerebral artery occlusion. Epileptic seizures occurred during follow-up in $9 \%$ of the carotid artery group and in $21.4 \%$ of the middle cerebral artery group. The different incidence of seizures in the two groups was statistically significant. The physiopathological mechanism of the late post-infarction epilepsy is discussed.

Epileptic seizures in cerebral arterial occlusive disease have been reported with an incidence varying from 10 to $28 \% .^{1-6}$ Previous studies reported that epileptic attacks are more frequent in internal carotid artery occlusion than in middle cerebral artery occlusion. ${ }^{36}$ However there is no clear distinction between early seizures which occur during the acute stage of an ischaemic disease because of biochemical reactions, ${ }^{7}$ and late recurrent seizures which represent a true post-infarction epilepsy. The aim of the present study was to evaluate the occurrence of late post-infarction epilepsy in patients with internal carotid artery or middle cerebral artery occlusion.

\section{Patients and methods}

Clinical data were collected retrospectively on 100 consecutive patients with angiographically proven internal carotid artery occlusion ${ }^{8}$ and on 70 patients with middle cerebral artery occlusion. ${ }^{9}$ Of the 100 patients, 93 were hospitalised for stroke ipsilateral to carotid occlusion and seven for ipsilateral transient ischaemic attacks. Of the $\mathbf{7 0}$

Address for reprint requests: Dr Piero De Carolis, Clinica Neurologica, Via Ugo Foscolo 7, 40123 Bologna, Italy.

Received 21 March 1984 and in revised form 24 May 1984. Accepted 1 June 1984 patients, 67 had been hospitalised for stroke ipsilateral to middle cerebral artery occlusion and three for ipsilateral transient ischaemic attacks. In the internal carotid artery group 13 died within the first month, 11 underwent surgery (end-arterectomy, by-pass operation) and were excluded, eight could not be traced. In the middle cerebral artery group 14 died in the acute stage of stroke. Therefore the follow-up data were obtained in 68 patients with internal carotid artery and 56 patients with middle cerebral artery occlusion by personal examination or by telephone interviews with the local physician (for those two who had died during the follow-up period).

The carotid group included 48 males and 20 females, aged 21 to 81 y (average 51.2). The follow-up period ranged from 1.5 to 5.9 y (median: $3.5 \mathrm{y}$ ). The middle cerebral artery group included 36 males and 20 females, aged 21 to 81 y (average 54.8). The follow-up ranged from 1 to 5 y (median: 5 y).

When at least one epileptic seizure occurred two weeks after stroke, late post-infarction epilepsy was considered. The single seizure was considered as epilepsy in accordance with criteria adopted for post-traumatic epilepsy,,$^{10-14}$ when a late seizure was diagnosed. Care was taken to exclude other possible causes of seizures (metabolic encephalopathy, encephalitis, chronic alcohol abuse, head trauma).

\section{Results}

Among the 68 patients with internal carotid artery 
Table 1 Occurrence of late seizures in patients with internal carotid artery and middle cerebral artery occlusion

\begin{tabular}{|c|c|c|c|c|}
\hline \multirow[t]{2}{*}{$\begin{array}{l}\text { Time of occurrence } \\
\text { following stroke }\end{array}$} & \multicolumn{2}{|c|}{$\begin{array}{l}\text { Internal carotid artery } \\
\text { occlusion }\end{array}$} & \multicolumn{2}{|c|}{$\begin{array}{l}\text { Middle cerebral artery } \\
\text { occlusion }\end{array}$} \\
\hline & $(N=6)$ & CUM \% & $(N=12)$ & CUM \% \\
\hline Within $1 \mathrm{yr}$ & 6 & 100 & 5 & $41 \cdot 6$ \\
\hline Within $2 \mathrm{yr}$ & 0 & - & 6 & 91.6 \\
\hline Within $3 \mathrm{yr}$ & 0 & - & 1 & 100 \\
\hline
\end{tabular}

occlusion, six (9\%) had epileptic seizures (partial motor seizure in two cases and secondarily generalised partial in four cases). Epileptic seizures occurred in $100 \%$ of cases from 3 to 6 months after the stroke. Among the 56 patients with middle cerebral artery occlusion, twelve $(21.4 \%)$ had epileptic seizures (both partial motor and secondarily generalised partial seizures in eight cases, only secondarily generalised partial seizures in four cases). None of the patients with transient ischaemic attacks on admission developed late epileptic seizure.

The epileptic seizures occurred in the middle cerebral artery group within the first year in five cases $(41.6 \%)$, within two years in six cases $(91.6 \%)$ and only in one case within the 3rd year $(100 \%)$. Statistical analysis revealed a greater incidence of seizures in the middle cerebral artery group as compared with the carotid group (six out of 68 in internal carotid artery group and 12 out of 56 middle cerebral artery group, $\mathrm{p}<0.05$ chi square test, Yates correction df 1).

The epileptic seizures are well controlled with anticonvulsant therapy (phenytoin, carbamazine) in both groups.

\section{Discussion}

In our study the incidence of post infarction epilepsy was higher in middle cerebral artery occlusion than in internal carotid artery occlusion, in disagreement with previous studies. ${ }^{36}$ It is difficult however to make a comparison with other reports since they did not distinguish early seizures from late epilepsy. The only finding in agreement with our study is that reported by Cocito et $\mathrm{al}^{6}$ of a higher frequency of "sequelar" seizures in the middle cerebral artery group than in the internal carotid artery group. We believe that a distinction is required between early and late seizures since early seizures are probably due to biochemical reactions provoked by ischaemia, ${ }^{7}$ whereas late seizures are due to chronic epileptic focus. Middle cerebral artery occlusion is more frequently of embolic origin ${ }^{15}$ and early recanalisation has been documented by serial angiographic studies. ${ }^{16}$ Pathological evidence suggests that most embolic infarcts are at least mini- mally haemorrhagic. ${ }^{17}$ Experimental studies 18-20 have shown the causative role of blood components (haemaglobin, ferritin, $\mathrm{Cl}, \mathrm{Fe}$ ) in the development of a chronic cortical epileptic focus. Therefore we can hypothesise that post-ischaemic epilepsy occurs more frequently in middle cerebral artery occlusion because of higher risk of haemorrhage in the cortical infarct. As reported for post-traumatic epilepsy, ${ }^{21}$ post-ischaemic epilepsy may also be an "iron epilepsy". Many other similarities can be found between post-ischaemic epilepsy and post-traumatic epilepsy: early seizures and late epilepsy are not directly related, ${ }^{22}{ }^{23}$ late seizures are more frequently generalised whereas early seizures are more frequently partial motor, ${ }^{22}{ }^{23}$ the onset of late epilepsy occurs in the majority of patients within two years from the time of brain damage. ${ }^{22} 23$

However, few studies have focused on late post ischaemic epilepsy as a medical problem. As has been done in post-traumatic epilepsy, further studies on late post-ischaemic epilepsy will be necessary in order to identify risk factors and consequently select candidates for prophylactic anticonvulsant trials.

\section{References}

${ }^{1}$ Johnson HC, Walker AE. The angiographic diagnosis of spontaneous thrombosis of the internal and common arterias. J Neurosurg 1951;8:631-59.

${ }^{2}$ Holmes JMD. L'histoire naturelle de l'occlusion de la carotide interne. Rev Neurol (Paris) 1963;109:17790.

${ }^{3}$ Silverstein A, Hollin S. Internal carotid Vs middle cerebral artery occlusion. Arch Neurol 1965;12:469-71.

${ }^{4}$ Lascelles RG, Burrows EH. Occlusion of the middle cerebral artery. Brain 1965;88:85-96.

5 Joyeux O, Aimard G, Goutelle A, Courson S, Perroudon $S$. Athérome carotidien segmentaire et épilepsie. Neurochirurgie (Paris) 1971;17:217-24.

- Cocito L, Favale E, Reni L. Epileptic seizures in cerebral arterial occlusive disease. Stroke 1982;13:189-95.

${ }^{7}$ Heiss WD, Hayakawa T, Waltz AG. Cortical neuronal function during ischemia. Arch Neurol 1976;33:81320.

${ }^{8}$ Sacquegna T, De Carolis P, Pazzaglia P et al. The clinical course and prognosis of carotid artery occlusion. $J$ Neurol Neurosurg Psychiatry 1982;45:1037-9.

- Sacquegna T, De Carolis P, Andreoli A et al. Long term prognosis after middle cerebral artery occlusion. $\mathrm{Br}$ Med J 1984;288:1490-1.

${ }^{10}$ Annegers JF, Grabow JD, Groover RV, Laws ER, Elveback LR, Kurland T. Seizures after head trauma: a population study. Neurology (Minneap) 1980;30:683-9.

"Jennett WB. Epilepsy after Non-missile Head Injuries. Ed 2, London, Heinemann Medical Books, 1975.

12 Walker AE, Jablon S. A Follow-up Study of Head Wounds in World War II. (VA Medical Monograph). 
Washington D.C., US Government Printing Office, 1961.

${ }^{13}$ Hendrick EB, Harris L. Post-traumatic epilepsy in children. J Trauma 1968;8:547-55.

14 Penfield W, Shaver M. The incidence of traumatic epilepsy and headache after head injury in civil practice. Res Publ Assoc Res Nerv Ment Dis $1945 ; 24: 620-34$.

15 Lhermitte F, Gautier SC, Derousné. Nature of occlusion of the middle cerebral artery. Neurology (Minneap) 1970;20:82-8.

16 Sindermann F, Dichgans J, Berglemer R. Occlusion of the middle cerebral artery and its branches: angiographic and clinical correlates. Brain 1969;92:60720.

${ }^{17}$ Cerebral embolism study group. Immediate anticoagulation of embolic stoke: a randomized trial. Stroke
1983;14,5:668-74.

18 Willmore LS, Sypert GW, Muson SB. Chronic focal epileptiform discharges induced by injection of iron into rat and cat cortex. Science 1978;200:1501-5.

${ }^{19}$ Lange SC, Neafsex ES, Wiler AR. Neuronal activity in chronic ferric chloride epileptic foci. Epilepsia 1980;21:251-4.

${ }^{20}$ Hammond EJ, Ramsay RE, Villareal HJ, Wilder DS. Effects of intracortical injection of blood components on the electrocotigram. Epilepsia 1980;21:3-14.

${ }^{21}$ Willmore LJ, Sypert GW, Munson SB. Recurrent seizures induced by cortical injection: A model of post traumatic epilepsy. Ann Neurol 1978;4:329-36.

${ }^{22}$ Louis J, McDowell F. Epileptic seizures in nonembolic cerebral infarction. Arch Neurol 1967;17:414-8.

${ }^{23}$ Jennet B. Post traumatic epilepsy. Advances in Neurology 1979;22:137-47. 